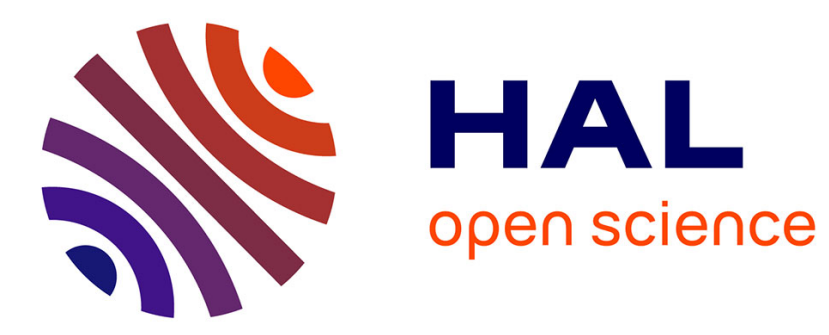

\title{
Polyaddition Synthesis Using Alkyne Esters for the Design of Vinylogous Urethane Vitrimers
}

Yann Spiesschaert, Jens Danneels, Niels van Herck, Marc Guerre, Guillaume Acke, Johan Winne, Filip Du Prez

\section{- To cite this version:}

Yann Spiesschaert, Jens Danneels, Niels van Herck, Marc Guerre, Guillaume Acke, et al.. Polyaddition Synthesis Using Alkyne Esters for the Design of Vinylogous Urethane Vitrimers. Macromolecules, 2021, 54 (17), pp.7931-7942. 10.1021/acs.macromol.1c01049 . hal-03347163

\section{HAL Id: hal-03347163 \\ https://hal.science/hal-03347163}

Submitted on 5 Oct 2021

HAL is a multi-disciplinary open access archive for the deposit and dissemination of scientific research documents, whether they are published or not. The documents may come from teaching and research institutions in France or abroad, or from public or private research centers.
L'archive ouverte pluridisciplinaire HAL, est destinée au dépôt et à la diffusion de documents scientifiques de niveau recherche, publiés ou non, émanant des établissements d'enseignement et de recherche français ou étrangers, des laboratoires publics ou privés. 


\section{Polyaddition synthesis using alkyne esters for the design of vinylogous urethane vitrimers}

Yann Spiesschaert, ${ }^{[a]}$ Jens Danneels, ${ }^{[a]}$ Niels Van Herck, ${ }^{[a]}$ Marc Guerre, ${ }^{[b]}$ Guillaume Acke, ${ }^{[c]}$ Johan Winne, ${ }^{[a]} *$ Filip Du Prez ${ }^{[a]} *$

[a] Polymer Chemistry Research Group and Laboratory for Organic Synthesis, Department of Organic and Macromolecular Chemistry, Faculty of Sciences, Ghent University, Krijgslaan 281 (S4), 9000 Ghent, Belgium

[b] Laboratoire des IMRCP, Université de Toulouse, CNRS UMR 5623, Université Paul Sabatier, 118 route de Narbonne, 31062 Toulouse Cedex 9, France

[c] Ghent Quantum Chemistry Group, Department of Chemistry, Faculty of Sciences, Ghent $\begin{array}{lllll}\text { University, } & \text { Krijgslaan } & 281 & \text { (S3), } 9000 \quad \text { Ghent, } & \text { Belgium }\end{array}$ *Corresponding author: Filip.DuPrez@UGent.be and Johan.Winne@UGent.be

Keywords: Covalent Adaptable Networks $\bullet$ Vitrimers $・$ Vinylogous Urethanes $•$ Alkyne Esters $\bullet$ Water-free

ABSTRACT: Vitrimers are a subclass of covalent adaptable networks, which introduce reshapeability and recyclability in thermoset materials while maintaining a high degree of chemical resistance and dimensional stability. Vitrimer materials based on vinylogous urethane (VU) chemistry have drawn a lot of attention in this area. Classically, these are obtained by the 
polycondensation polymerization of acetoacetate and amine monomers. Unfortunately, this also releases water, often leading to porosity defects in the initially obtained non-reprocessed crosslinked materials. Here, we demonstrate that alkyne esters (AE) can be used as alternative building blocks for VU vitrimers by a polyaddition polymerization with amines, leading to water-free formulations and straightforward access to defect-free cured VU vitrimer materials. The bond formation and dynamic bond exchange was also studied by small molecule reactions, further rationalized by a computational (DFT) approach. The resulting water-free VU vitrimers display similar material properties compared to vitrimers based on acetoacetates, although also some differences are seen, which can be related to a minor amide-bond forming side reaction. Furthermore, using this novel $\mathrm{AE}$ approach, polyaddition curing of $\mathrm{VU}$ epoxy vitrimers can easily be prepared in a one-pot three-component method, combining AE, amine and epoxy monomers. This study shows that AE monomers can be used as an easy drop-in method to obtain processable epoxy materials with tunable viscoelastic properties, where the viscous flow behavior can in principle be fully tuned by varying the monomers' ratios and compositions.

\section{Introduction}

Polymer materials are generally divided into two classes depending on their thermal flow behaviour, i.e. either thermosets or thermoplastics. However, this distinction has been confounded by the introduction of covalent adaptable networks (CANs) $)^{1-3}$ and more in particular vitrimers, which defy classification into either class. ${ }^{4-10}$ Indeed, vitrimers are permanent crosslinked materials that are able to change their network topology, thus introducing reshapeability and recyclability in thermosets, without losing network connectivity. This is made possible by the introduction of dynamic covalent bonds that follow a thermally responsive associative exchange mechanism (i.e. an addition/elimination pathway), meaning that first a new covalent 
bond needs to be formed before an already existing one can be broken. ${ }^{4}$ Since their discovery in 2011, a wide variety of chemistries have been investigated for this purpose ranging from transesterification, ${ }^{10-19}$ transalkylation of trialkylsulfonium salts, ${ }^{20}$ boronic ester transesterification $^{21-25}$ to the vinylogous urethane transamination ${ }^{26-36}$ and many more..$^{37-44}$

The vinylogous urethane (VU) chemistry was first introduced in vitrimer materials by our research group in 2015.32 In the latter studies, VU vitrimers were synthesised via the polycondensation reaction between acetoacetates (AA) and amines with the release of water (Scheme 1a).

a) Acetoacetate as vinylogous urethane precursor moiety ${ }^{25-36 ; 45-48}$

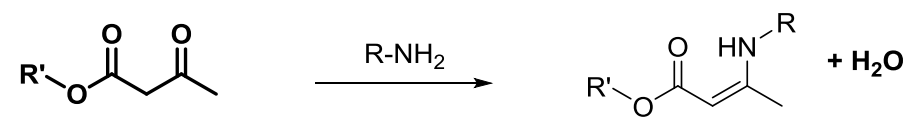

b) Thioacetal formation ${ }^{49}$

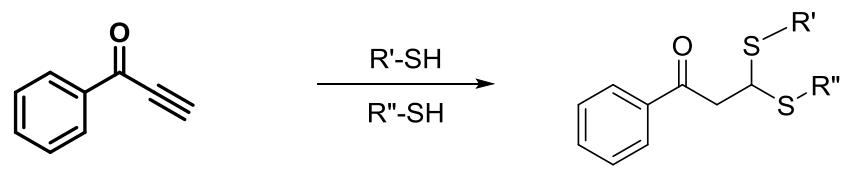

c) This work: Alkyne ester as vinylogous urethane precursor moiety

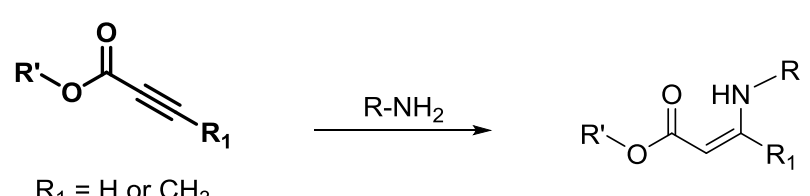

Scheme 1: Schematic overview of (a) the acetoacetate based VU platform, (b) the activated alkynone-based chemistry for CANs' preparation ( c) the herein described alkyne ester-based VU chemistry route.

Ever since its introduction, the VU vitrimer chemistry has been picked up by several other research groups, also industrial ones, ${ }^{45}$ in view of its straightforward implementation in many polymer matrices, and their intrinsic diversity. ${ }^{26,29,46-48}$ However, a principal technical bottleneck 
in the application of this chemistry, is its polycondensation nature, often giving rise to defects in cured VU networks, due to the release of water and formation of bubbles in freshly cured samples, generating porosity throughout the material. This porosity can be avoided by prepolymerization approaches ${ }^{33}$ or it can also be generally erased using an additional processing step, e.g. consisting of compression moulding. ${ }^{32}$

Nonetheless, for certain applications, this additional processing step is not desired or even feasible (e.g., composite materials or 3D-printing) and thus, the VU chemistry in vitrimers can be troublesome for such specific applications. Prepolymerization provides an effective technical solution, as release of water and network formation can be separated, to obtain porosity-free networks by designing an oligomeric VU curing agent, as recently shown in our synthesis of VU-based epoxy vitrimers.33 However, the obtained oligomeric (VU prepolymer) epoxy curing agents display a high viscosity, again giving a technically troublesome epoxy curing process, as monomer mixing is difficult. For this and other reasons, we have long been interested in developing an alternative synthetic methodology to obtain water-free VU vitrimers via a more application-friendly polyaddition process for network design.

Recently, our group reported the use of alkynones as monomers for novel thiol-ene based CAN materials. ${ }^{49}$ In this work, thioacetals were obtained from the double thiol-Michael addition between activated alkynones and thiols (Scheme 1b). Such alkynone precursors allow the formation of a polymer network in a water-free manner as they react via an addition reaction instead of a condensation reaction. While alkyne esters (AE) are well-known precursors in organic chemistry for the preparation of VU compounds via an aza-Michael reactions, ${ }^{50,51}$ this chemistry is also not readily applicable for polymer synthesis, as it is also known to undergo irreversible side reactions, such as swift amidation reactions, producing alkyne amides in high 
yields. ${ }^{52,53}$ Alkyne esters are highly reactive monomers, and amines are highly reactive nucleophiles as well as bases, and their combination has so far proven troublesome in our ongoing studies in the VU area. From these initial studies, it became clear that a good reaction design and understanding of the reactivity parameters is necessary in order to supress side reactions and thus favour the VU-formation (Scheme 1c).

Here, we will report the first successful syntheses of VU vitrimers, using the attractive polyaddition methodology. First, small molecule reactivity studies have been performed to gain a better understanding of the possible reaction pathways between $\mathrm{AE}$ and amines and to evaluate the VU-precursor viability of AE. Furthermore, density functional theory (DFT) calculations were performed to further rationalise the experimental results obtained regarding VU formation in terms of steric and electronic influence and to investigate this influence on the transamination reaction. Following this, experimental transamination studies were also performed to corroborate the theoretical data. Based on our improved understanding of the underlying chemistry, we were able to tackle VU vitrimer synthesis via polyaddition polymerisations of AE monomer, including interesting VU-hardened epoxy vitrimers. The recycling potential and stress-relaxation behaviour of this new generation of vitrimers was also examined, and critically compared to that of their AA-based VU vitrimer counterparts.

\section{Results and Discussion}

\section{Amine - Alkyne ester model study: determination of possible side reactions during VU formation}

In the introduction, it was mentioned that alkyne esters can undergo an acyl substitution

reaction leading to the formation of alkyne amides. Hergenrother and co-workers ${ }^{\mathbf{5 2 5 3}}$ demonstrated this by obtaining alkyne amides in high yield (up to $94 \%$ ) from reactions performed with a slight excess of amine compared to the alkyl ester (1.2:1 $\left.\mathrm{NH}_{2}: \mathrm{AE}\right)$. Based on 
the reported reaction conditions $\left(0^{\circ} \mathrm{C}\right.$; methanol as solvent), it was hypothesized that the acyl substitution might be favored in a protic solvent over the aza-Michael addition reaction. Since the herein envisioned VU synthesis procedures will be performed in bulk at elevated temperatures, this undesired substitution reaction was expected to exhibit a different reactivity profile. In order to investigate this, a model study was performed to determine the percentage of alkyne amide product formed on the one hand and whether the reaction efficiency was high enough to obtain VU materials on the other hand.

For this, 1-pentanol functionalized with an AE-function (1-Pentanol-AE) was reacted in bulk at $60{ }^{\circ} \mathrm{C}$ for $16 \mathrm{~h}$ with three different butylamine/AE ratios (i.e. (1.1:1), (1:1) and (0.9:1)) (Figure 1a). Butylamine was chosen since it can be easily removed using rotary evaporation, thus allowing sample analysis by LCMS without the need for additional purification, which could remove possible side-products. In each case, the desired vinylogous urethane was found to be the major product, corroborating the stated hypothesis that a protic solvent assists the acyl substitution reaction. Nevertheless, besides trace amounts of the starting compound 1-PentanolAE and the expected VU (EVU), one side-product could also be detected in LCMS and NMR analysis (Figure 1b and Figure S.2), namely the alkyne amide (AmS). As expected, the reduction of the amount of butylamine resulted in a higher percentage of 1-pentanol-AE in the reaction mixture, up to a maximum of $18 \%$ compared to EVU for the reaction using a 0.9:1 ratio (Figure $1 \mathrm{~b}$ and Figure S.2). Interestingly, the ratio of the alkyne amide to the desired VU-compound remained constant throughout the different reactions, i.e. roughly $7 \%$ (as determined by NMR). 
The presence of such alkyne amide functions would most likely result in a fraction of network defects and thus a potentially higher soluble fraction of the resulting vitrimer materials. Nevertheless, since no vinylogous urea signals were observed, the required excess of primary amines for transamination to the VU-functions is expected to be still present in the networks and vitrimer properties should thus be observed. Therefore, the AE moiety was still considered as a viable VU precursor for the synthesis of water-free VU vitrimers.

a)

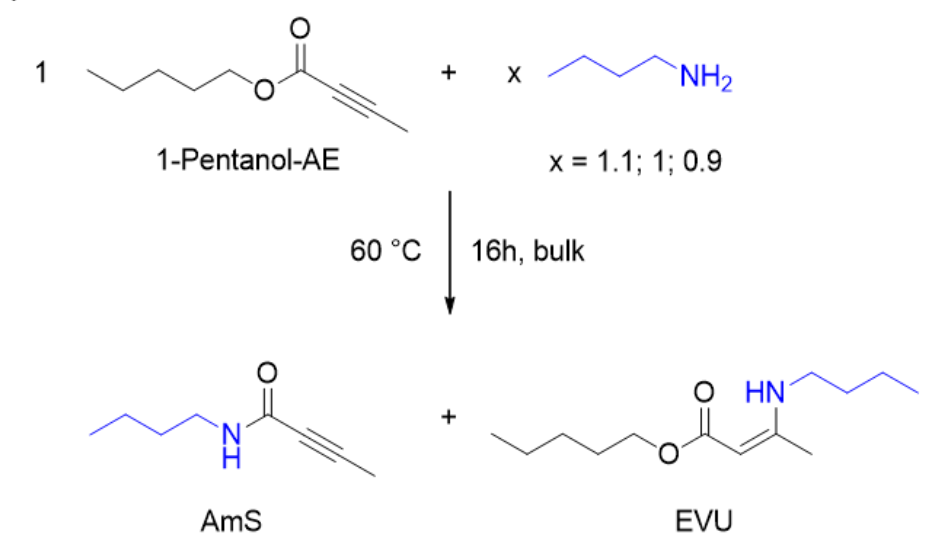

b)

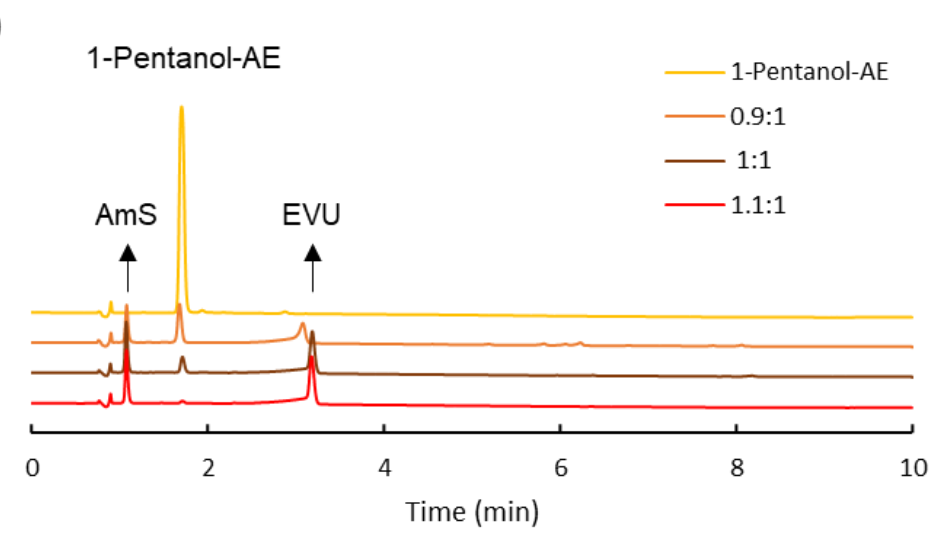

Figure 1: a) Model study reaction between 1-pentanol-AE and different ratios of butylamine leading to the expected vinylogous urethane compound (EVU) and an amide side-product (AmS). b) LCMS chromatograms $(\lambda=214 \mathrm{~nm})$ of 1-pentanol-AE (as a reference) and the 
products of the reactions performed with different ratios of $\mathrm{NH} 2$ :AE. The samples were analysed at a solvent gradient of $75 \% \rightarrow 100 \%$ water $\rightarrow$ acetonitrile.

\section{Computational study of the AE-based chemistry}

In the above-described model study, it was observed that the reaction between amines and AEs was more exothermic than the reaction between amines and AAs. Due to the higher reactivity of the AE towards amines, previously discarded amines - such as aromatic amines - could now potentially be utilised to obtain VU vitrimers. To be able to test this hypothesis as efficiently as possible at the material level, we first computationally investigated the range of amines that can be used for the VU synthesis. All calculations were performed using the Gaussian 16 package ${ }^{54}$ with the M06-2X/6-311+G(d,p) level of theory, as this functional performs well for thiolMichael reactions, ${ }^{55}$ which can be considered to be rather similar to the here investigated AzaMichael reactions. The CPCM implicit solvent $\operatorname{model}^{56}$ was utilised to take the effects of solvent - in this case chloroform - into account, as zwitterionic species in the gas phase are not possible without delocalisation. Gibbs free energy profiles for both the VU formation reaction (starting from $\mathrm{AA}$ and $\mathrm{AE}$ ) and for the transamination reaction between an amine and a $\mathrm{VU}$ were obtained, directly leading to the relative Gibbs free energy $\left(\Delta \Delta \mathrm{G}^{0}\right)$ and the relative Gibbs free energy of the transition state $\left(\Delta \mathrm{G}^{0, \hat{t}}\right)$ of the rate limiting step of the pathway. Scheme 2 represents a summary of the calculations that have been performed, including the different mechanistic pathways (Scheme $2 \mathrm{a}-\mathrm{b}$ ) and the investigated amines (Scheme 2c). 
a) Vinylogous urethane synthesis from alkyne esters

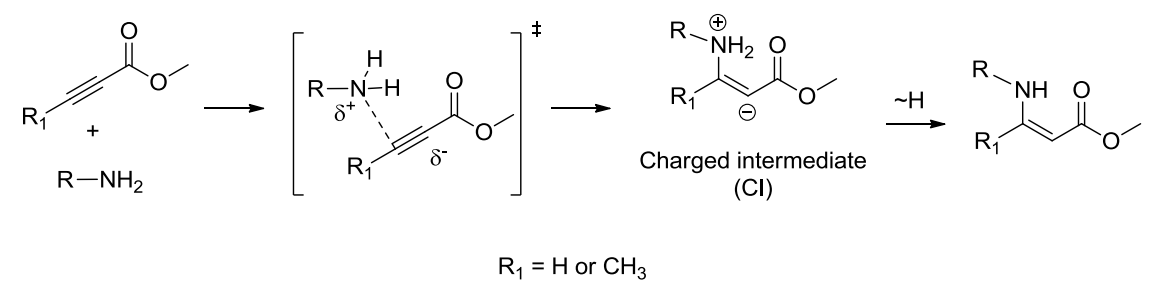

b) Vinylogous urethane synthesis from acetoacetates

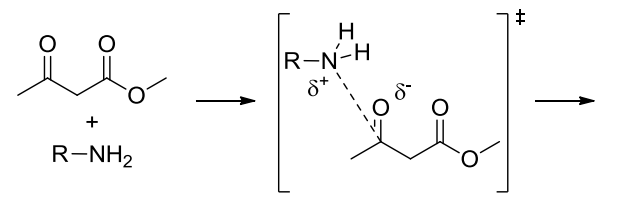

2)
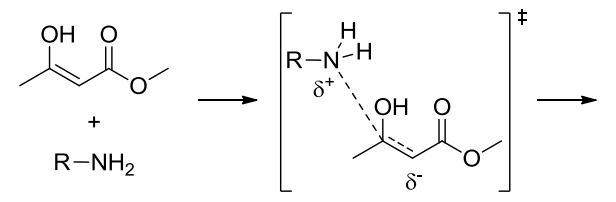

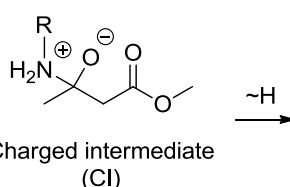

$(\mathrm{Cl})$

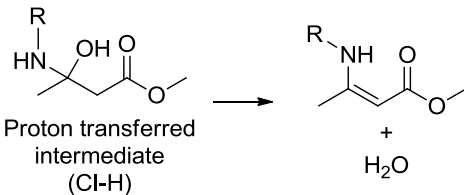

(Cl-H)

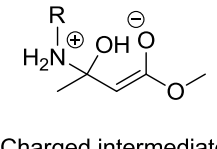

(CI)

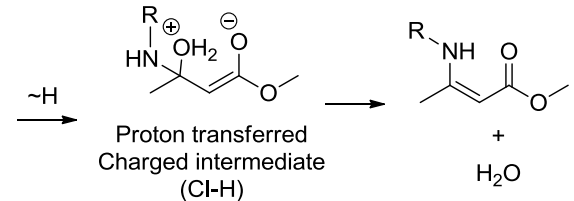

c) Amines used in the computational study
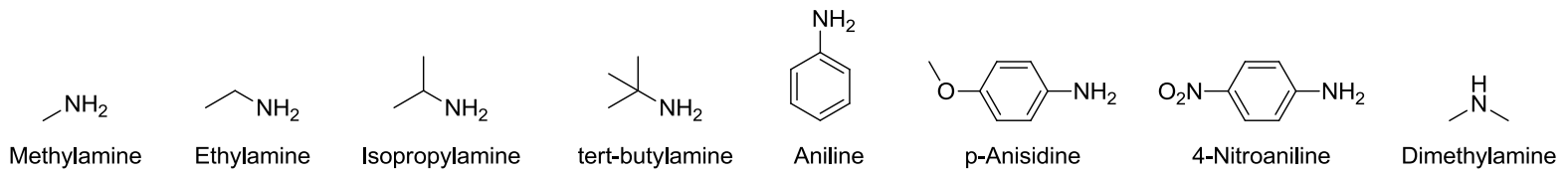

Scheme 2: General mechanisms of the vinylogous urethane formation starting from a) alkyne esters and b) acetoacetates in both the keto (1) and enol (2) tautomer and a primary amine. (c) Amines used during the computational study.

The broad range of different amines, ranging from methylamine to 4-nitroaniline, were chosen to investigate both steric and electronic influences, as to further quantify and rationalise their difference in reactivity. To reduce the complexity of the calculations, simplified versions of both the amines and the $\mathrm{AA}$ or $\mathrm{AE}$, compared to their experimental used counterparts, such as methyl but-2-ynoate (Me-AE), methyl acetoacetate (Me-AA) and methylamine, were investigated. Furthermore, the reported results are related to the formation of VU in the cis-product, despite the fact that, theoretically and practically, the trans-product can also be formed ${ }^{57}$ Nevertheless, 
the cis-product is always the major product, due to the extra stabilisation via an internal hydrogen bond, and was therefore chosen to represent the vinylogous urethane moiety in the performed calculations.

The calculation results concerning the VU formation based on Me-AE and Me-AA in its enol tautomer form, as well as those obtained for the transamination of ethyl VU with the amines (Scheme 2c), can be found in Table 1 and in the supporting information (section V.2). Based on the thermodynamic profile of each individual reaction pathway, one can already distinguish the following predictive trends for the VU formation for both Me-AE and Me-AA. First, thermodynamic driving force could be the sole cause of potential differences in reactivity as reactions between amines and Me-AE are all highly exergonic $\left(\Delta \Delta \mathrm{G}^{0}<-95 \mathrm{~kJ} / \mathrm{mol}^{-1}\right)$ (Table 1 and Figure 2). On the other hand, the reactions with Me-AA are mostly exergonic $\left(-30 \mathrm{~kJ} / \mathrm{mol}^{-1}<\right.$ $\Delta \Delta \mathrm{G}^{0}<15 \mathrm{~kJ} / \mathrm{mol}^{-1}$ ) and thus have a much lower thermodynamic driving force (Table 1 and Figure S.34) and only minor differences in the $\Delta G^{0, \ddagger}$ values between the two monomers were obtained. Second, increasing the steric hindrance of the primary amine (from methylamine to tert-butylamine) results in a higher kinetic barrier and reduced thermodynamic driving force for the VU formation. Third, tuning the nucleophilicity of the amine by using electron donating/withdrawing groups is expected to play an important role in the VU formation. Indeed, by introducing electron donating (eg methoxy group in $p$-anisidine) or withdrawing (eg nitro group in 4-nitroaniline) groups, the $\Delta \mathrm{G}^{0, \$}$ value was lowered or increased respectively compared to the reaction with aniline. This can be explained by the fact that $p$-anisidine is more nucleophilic because of the delocalisation of an electron pair introduced by the methoxy group, whereas the nucleophilicity is lowered for 4-nitroaniline as the electrons are drawn towards the nitro group. Lastly, secondary amines display the lowest $\Delta G^{0, \$}$, as expected from their higher 
nucleophilicity, but they also display the lowest thermodynamic driving force of all the investigated aliphatic amines, due to their inability to form internal hydrogen bonds for extra stabilisation. Therefore, they are expected to be under kinetic control.

Table 1: Calculated Gibbs free energies of the vinylogous urethane formation normalized to the respective starting compounds (neutral amine and neutral AA or AE) and of the transamination reaction, following the protic iminium pathway and aprotic Aza-Michael pathway of ethyl VU normalized to the respective starting compounds (for the iminium pathway: positively charged amine and neutral VU as shown in Figure 3; for the aprotic pathway: neutral amine and neutral VU as shown in Figure S.39).

\begin{tabular}{|c|c|c|c|c|c|c|c|c|}
\hline & \multicolumn{4}{|c|}{ VU Formation } & \multicolumn{4}{|c|}{$\begin{array}{c}\text { Transamination } \\
\text { of } \\
\text { Ethyl VU }\end{array}$} \\
\hline & \multicolumn{2}{|c|}{ Methyl but-2-ynoate } & \multicolumn{2}{|c|}{$\begin{array}{c}\text { Methyl acetoacetate } \\
\text { (enol) }\end{array}$} & \multicolumn{2}{|c|}{ Protic iminium } & \multicolumn{2}{|c|}{$\begin{array}{c}\text { Aprotic } \\
\text { Aza-Michael }\end{array}$} \\
\hline & $\begin{array}{c}\Delta \mathrm{G}^{0, \$} \\
\left(\mathrm{~kJ} \cdot \mathrm{mol}^{-1}\right)\end{array}$ & $\begin{array}{l}\Delta \Delta \mathrm{G}^{0} \\
\left.\mathrm{~kJ} \cdot \mathrm{mol}^{-1}\right)\end{array}$ & $\left(\mathrm{kJ} \cdot \mathrm{mol}^{-1}\right)$ & $\begin{array}{l}\Delta \Delta \mathrm{G}^{0} \\
\left.\mathrm{~kJ} \cdot \mathrm{mol}^{-1}\right)\end{array}$ & $\begin{array}{c}\Delta \mathrm{G}^{0, \ddagger, \mathrm{a}} \\
\left(\mathrm{TS}_{1}\right) \\
\left(\mathrm{kJ} \cdot \mathrm{mol}^{-1}\right)\end{array}$ & $\begin{array}{l}\Delta \Delta \mathrm{G}^{0} \\
\left(\mathrm{~kJ} \cdot \mathrm{mol}^{-1}\right)\end{array}$ & $\begin{array}{c}\Delta \mathrm{G}^{0, \downarrow, \mathrm{a}} \\
\left(\mathrm{TS}_{1}\right) \\
\left(\mathrm{kJ} \cdot \mathrm{mol}^{-1}\right)\end{array}$ & $\begin{array}{l}\Delta \Delta \mathrm{G}^{0} \\
\left(\mathrm{~kJ} . \mathrm{mol}^{-1}\right)\end{array}$ \\
\hline Methylamine & 117.1 & -142.1 & 107.6 & -29.5 & 37.7 & -7.7 & 144.7 & 4.0 \\
\hline Ethylamine & 118.3 & -139.1 & 109.4 & -26.5 & 41.9 & 0.0 & 146.0 & 0.0 \\
\hline Isopropylamine & 116.51 & -135.1 & 114.7 & -22.6 & 49.4 & 5.0 & 149.8 & 4.0 \\
\hline Tert-butylamine & 125.2 & -114.3 & 133.2 & -1.7 & 60.0 & 27.9 & 170.3 & 24.8 \\
\hline Aniline & 142.2 & -113.2 & $*$ & -0.7 & 11.1 & -28.2 & 170.2 & 37.7 \\
\hline p-Anisidine & 135.4 & -120.9 & * & -8.4 & $*$ & -23.0 & 162.9 & 18.2 \\
\hline 4-Nitroaniline & 164.4 & -97.6 & * & 14.9 & $*$ & -53.9 & 192.2 & 41.5 \\
\hline Dimethylamine & 107.3 & -104.7 & 99.9 & 7.8 & 45.6 & 42.8 & 136.8 & 34.4 \\
\hline
\end{tabular}

* Calculations did not converge or displayed wrong frequencies. Therefore, the Gibbs free energy could not be calculated.

${ }^{a}$ Value of the first transition state, which is not necessarily the one of the rate determining step. 


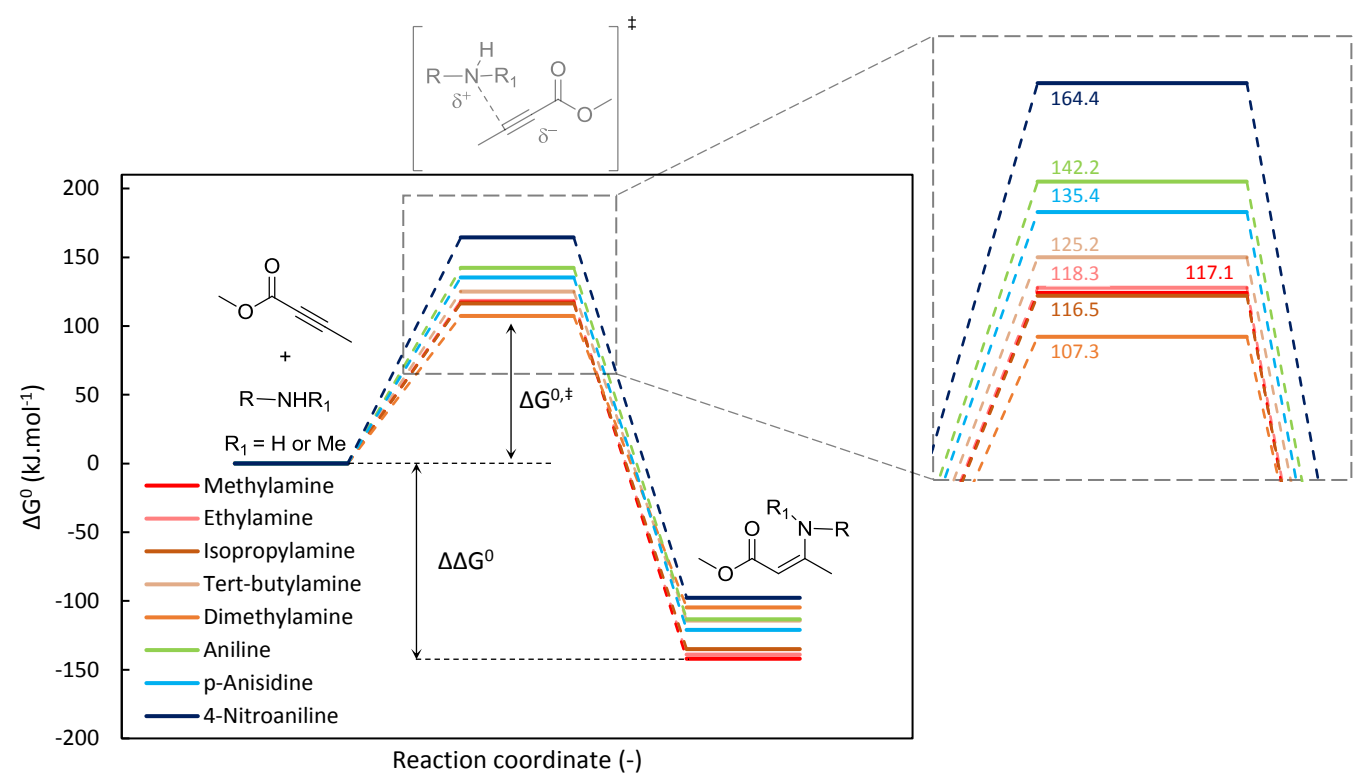

Figure 2: Calculated free energy diagram for the reaction between methyl but-2-ynoate and different amines, with a focus on the transition state and without the intermediate states. The zoomed section highlights the difference in $\Delta \mathrm{G} 0, \ddagger$.

As these computational results indicate that steric and electronic effects could play an important role, we then investigated the transamination computationally. Moreover, since the VU transamination can occur via two distinct mechanisms, namely an Aza-Michael (Figure S.38) and an iminium pathway (Figure 3 and Figure S.42), ${ }^{30}$ they were both investigated. The results of the calculations for the reaction between ethyl VU and the investigated amines via both pathways can be found in Table 1, Figure 3 and Figure S.39) The same calculations were also performed for the other VU, however, as similar trends were obtained, they will not be discussed in more detail and the results can be found in the supporting information (section V.2.2-V.2.4). 


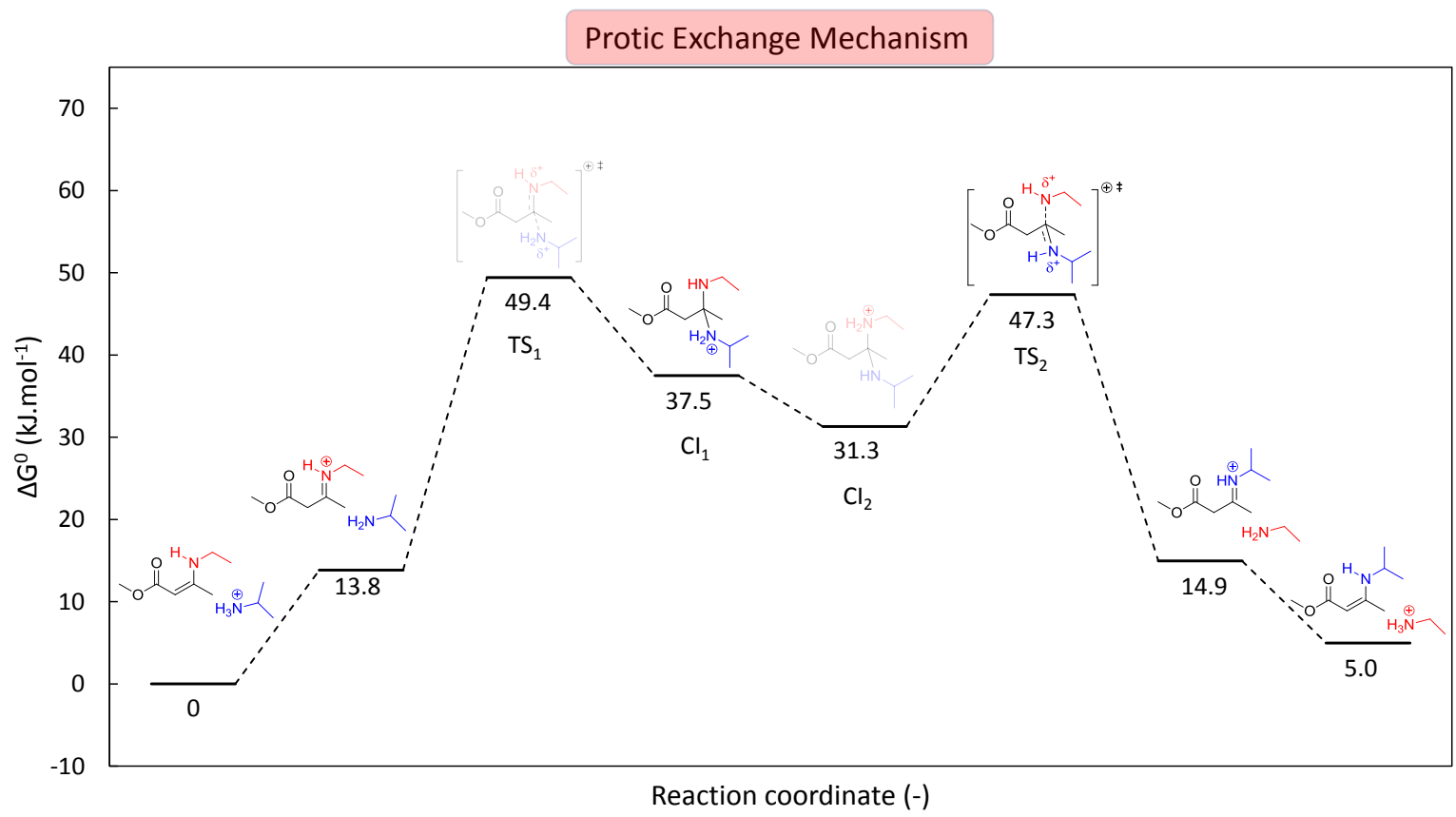

Figure 3: Calculated free energy profile for the transamination reaction of methyl-3(ethylamino)but-2-enoate with isopropylamine, following the protic iminium pathway in chloroform.

In Table 1 , one can see that the $\Delta \mathrm{G}^{0, *}$ values for Aza-Michael are much higher than the ones calculated for the iminium mechanism. These high values for the Aza-Michael pathway are in agreement with experimental results observed in previous studies when comparing the viscous flow activation energy. ${ }^{27,30,34,35}$ Although relating thermodynamic profiles of individual reaction pathways to experimental results is open to interpretation, the values calculated here provide a possible rationalization for the experimentally obtained results, which indicate that the Michaelpathway indeed has a high kinetic energy barrier.

Furthermore, similar to the VU formation results, increasing the steric hindrance of the amines increases the kinetic energy barrier (higher $\Delta \mathrm{G}^{0,}$ values) and generally lowers the thermodynamic driving force (more positive values of $\Delta \Delta \mathrm{G}^{0}$ ) of both pathways. Especially the 
transamination with sterically hindered amines does not seem to be favoured, whereas nonsterically hindered amines (e.g. tert-butylamine, Table S.8 and S.16) could lead to an irreversible transamination reaction and therefore a non-dynamic system. Interestingly, despite the fact that the formation of aromatic VU is thermodynamically unfavoured, the transamination reaction via the protic iminium pathway seems to be highly preferred and this shows a very low kinetic energy barrier. The high exothermicity of the transamination reaction with aromatic amines (e.g. aniline) can be explained by the fact that the ground states, as mentioned above, involve protonated amines. Since aniline and its derivatives are rather acidic, they prefer to donate a proton instead of accepting one. Therefore, it stands to reason that the low activation energy combined with the ease of proton transfer and aniline's aversion to be protonated could lead to potential exchange between aromatic amines and VU from aliphatic amines. This could be a possible way to introduce aromatic amines in a VU matrix, instead of directly synthesising aromatic VU from AA or AE precursors. Moreover, due to the high difference in $\Delta \mathrm{G}^{0,}$ and $\Delta \Delta \mathrm{G}^{0}$ values, the exchange would indeed most likely follow an iminium pathway instead of an Aza-Michael mechanism, as there would be no thermodynamic driving force for the reaction to $\operatorname{occur}\left(\Delta \Delta \mathrm{G}^{0}>0 \mathrm{~kJ} \cdot \mathrm{mol}^{-1}\right)$.

Additionally, the electronic influence also follows a similar trend as observed for the VU synthesis. Electron donating groups, which increase the amine's nucleophilicity, reduce the energy required to reach the transition state and lead to more favourable $\Delta \Delta \mathrm{G}^{0}$ values. Alternatively, electron withdrawing groups raise both the $\Delta \mathrm{G}^{0, \$}$ and $\Delta \Delta \mathrm{G}^{0}$ values, making it more difficult for transamination to occur. Lastly, despite the lower $\Delta \mathrm{G}^{0, \$}$ value obtained for dimethylamine, no transamination will occur in a reaction with ethyl $\mathrm{VU}$, as $\Delta \Delta \mathrm{G}^{0}$ value is not in favour of dimethyl VU formation, as could be expected due to the lack of internal hydrogen bond 
stabilisation effects. However, transamination reactions should be possible with aromatic VU following the Aza-Michael pathway, since this reaction is thermodynamically favoured $\left(\Delta \Delta \mathrm{G}^{0}=\right.$ $\left.-3.3 \mathrm{~kJ} . \mathrm{mol}^{-1}\right)$ (Table S.6).

The obtained results are highly interesting as they suggest that mixing amines of different steric and electronic nature could be a way to tune the viscous flow behaviour of vinylogous urethane systems. Moreover, by smartly designing the system it might also be possible to deactivate the viscous flow after one processing step. This would allow the formation of a permanent network during usage, but having chemical recycling capability. In order to corroborate the obtained calculated results, some transamination and VU synthesis reactions were also performed, as described in the following section.

\section{Steric and electronic influences on the transamination}

As shown in the computational study, both the steric and electronic properties of the amines can have a large impact on their reactivity. Indeed, the reaction of aromatic amines, as well as amines on a tertiary carbon with $\mathrm{AE}$ and AA are clearly less thermodynamically favoured compared to aliphatic primary amines. Nevertheless, attempts were made to synthesise these VU's in bulk, preferably without the addition of a catalyst. The results showed no decent conversions when using AA. However, using AE functionalised 1-pentanol, it was possible to obtain a VU from tert-octylamine in high yield after a reaction carried out $24 \mathrm{~h}$ at $100{ }^{\circ} \mathrm{C}$ and $72 \mathrm{~h}$ at $120{ }^{\circ} \mathrm{C}$ under $\mathrm{N}_{2}$ atmosphere (yield $=81 \%$ after purification). Following this, the preparation of an aromatic $\mathrm{VU}$ was attempted from the reaction between aniline and 1-pentanol-AE using similar conditions. The attempts were unsuccessful, even with harsher reaction conditions, as

justified by the higher $\Delta \mathrm{G}^{0, \$}$. Therefore, the use of catalysts was investigated. Using 1,5,7triazabicyclo[4.4.0]dec-5-ene (TBD) as a catalyst at $100{ }^{\circ} \mathrm{C}$ for $24 \mathrm{~h}$ led to the formation of the 
desired aromatic VU with a yield of $75 \%$ after purification. Other acid or basic catalysts (i.e. ptoluene sulfonic acid (pTsOH), 1,8-diazabicylo[5.4.0]undec-7-ene (DBU) and tetramethylguanidine (TMG)) were also investigated without success.

The computational predictions are in agreement with these experimental results, providing further support for the plausibility of the performed calculations, and show that amines that were previously disregarded could finally be utilised for the formation of VU vitrimers with optimised reaction conditions (e.g. using solvent and appropriate catalyst). Following these model compound syntheses, transamination studies were performed (Figure 4a). 
a) General transamination reaction scheme

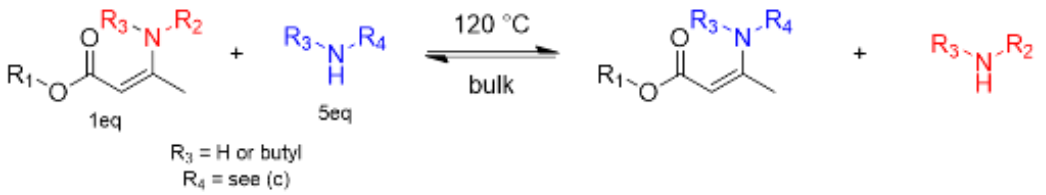

b) Vinylogous urethane utilised in the experimental transamination study

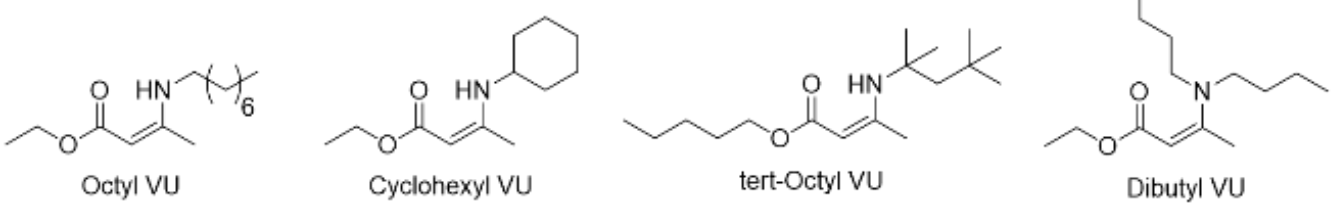

c) Amines utilised in the experimental transamination study
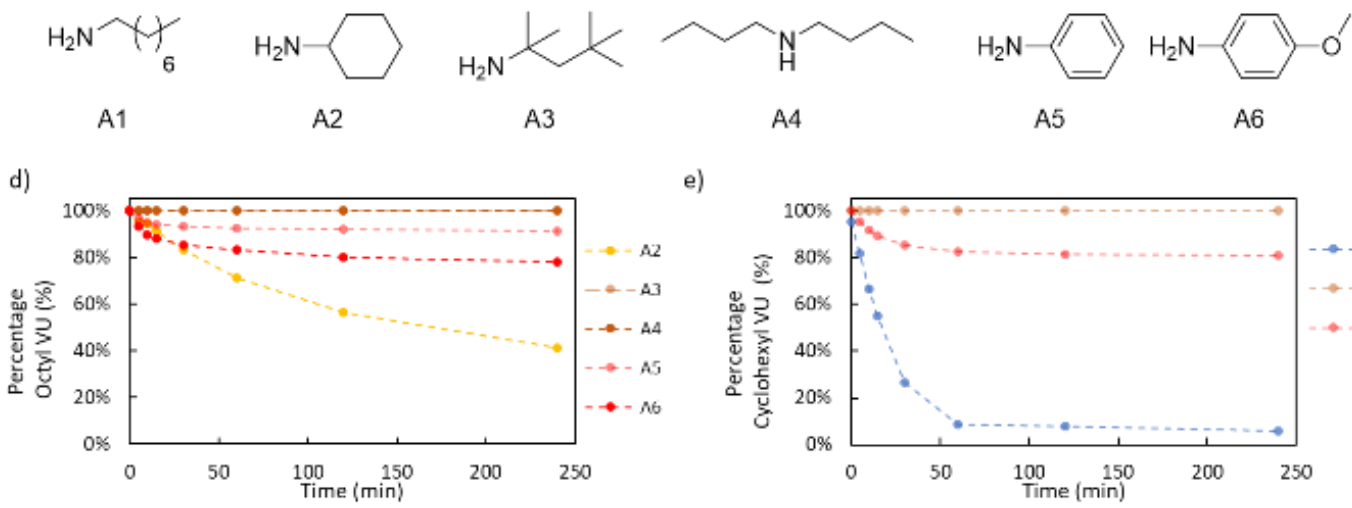

e)
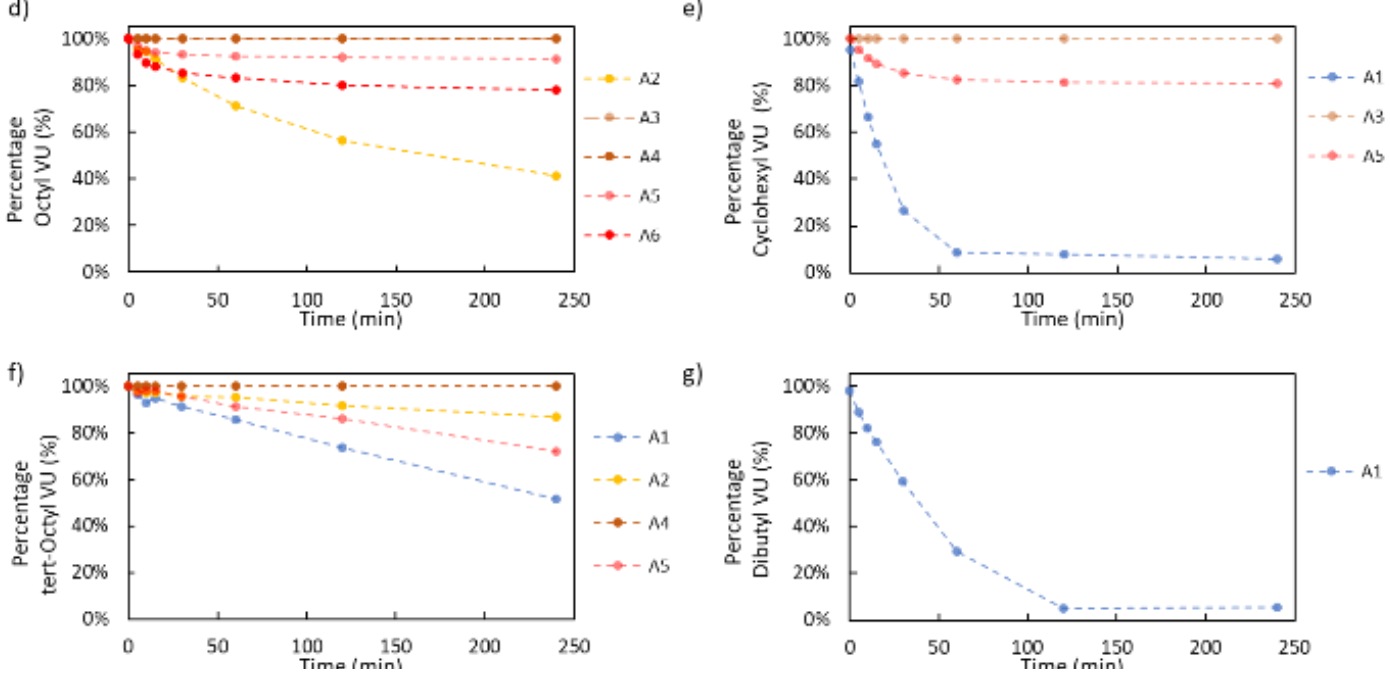

Figure 4: a) General reaction scheme of the investigated transamination model studies in d-g. b \& c) The utilized VU compounds (b) and amines (c). d-g) Model studies in which the disappearance of the VU was followed via NMR measurements as a function of time through exchange reactions with different amines in bulk at $120{ }^{\circ} \mathrm{C}$ using a five-fold excess of amines.

The investigated VUs are d) ethyl-3-(octylamino)but-2-enoate (octyl VU), e) ethyl-3(cyclohexylamine)but-2-enoate (cyclohexyl VU), f) pentyl-3-(tert-octylamino)but-2-enoate (tertoctyl VU) and g) ethyl-3-(dibutylamino)but-2-enoate (dibutyl VU). 
First, four different VU were synthesised, each based on a different sterically hindered amine (Figure 4b). These were then mixed with a five-fold excess of a specified amine taken from the range shown in Figure $4 \mathrm{c}$ and heated to $120{ }^{\circ} \mathrm{C}$ in bulk (Figure 4a). In figures $4 \mathrm{~d}-\mathrm{g}$ and Table S.1, the different transamination reactions are represented as the remaining percentage of the starting VU as a function of time.

The theoretical calculations for the aliphatic primary amines (octylamine (A1), cyclohexylamine (A2) and tert-octylamine (A3)) were in good agreement with the experimental results, i.e. the least sterically hindered amine reacts the fastest and forms the most preferred VU, as clearly visible in Figure 4d-g. Indeed, both A1 and A2 readily perform transamination whereas no transamination product of A3 could be distinguished. A possible explanation for the lack of reaction could be linked to both kinetic (higher kinetic barrier to reach the transition state) and thermodynamic issues (unfavourable $\Delta \Delta \mathrm{G}^{0}$ values), related to the amine being greatly sterically hindered. Following this, the reaction between tert-octyl VU and A1 and A2 seems to be rather slow (Figure 4f), despite being clearly favoured towards the newly formed VU compounds according to the DFT calculations (Table S.8 and S.16). A possible explanation could be found in the steric hindrance of the tert-octyl group, which increases the kinetic energy barrier and could slow down possible attack of the amines and thus decreases the reaction rate, since equilibrium was not obtained after $4 \mathrm{~h}$. Furthermore, as predicted by the computational results, no transamination product of the reaction with dibutylamine (A4) could be observed as this would be a thermodynamically unfavoured reaction due to the lack of internal hydrogenbonding stabilisation (e.g. a $\Delta \Delta \mathrm{G}^{0}=42.8 \mathrm{~kJ} \cdot \mathrm{mol}^{-1}$ for the transamination between ethyl VU and dimethylamine as shown in Table 1). However, it needs to be mentioned that these studies were followed via off-line NMR. This means that some exchange product could have been formed but, 
despite the high excess of amine, the backwards reaction into the more stable VU could have occurred before the NMR measurement was performed.

Furthermore, the aromatic amines (aniline (A5) and $p$-anisidine (A6)) did participate in exchange reactions, which is rather surprising as obtaining aromatic VU compounds was previously found to be quite difficult, ${ }^{58}$ but was here anticipated based on the calculations. Moreover, changing from octyl VU to cyclohexyl VU to tert-octyl VU (resulting in less thermodynamically stable VU) was also accompanied by increasing fractions of aromatic VU (Figure 4d-f and Table S.1), with the equilibrium fraction probably being even higher than $28 \%$ (for A5) in the reaction with tert-octyl VU, as equilibrium was not yet reached after 4 hours. Additionally, substituting A5 for its more nucleophilic counterpart of A6, also resulted in a larger equilibrium fraction of aromatic VU (Figure 4d), in line with the computational predictions as seen in Table 1 and SI section V.2.1.

In a next step, the activation energy of the transamination reaction between octyl VU and A2 $\left(56.7 \pm 4.6 \mathrm{~kJ} \cdot \mathrm{mol}^{-1}\right)$ and vice-versa $\left(80.3 \pm 3.2 \mathrm{~kJ} \mathrm{~mol}^{-1}\right)$ was determined following the method described in the supporting information (Section III.15). As expected, a significant difference was obtained, which could potentially be explained by different stabilisation effects leading to the transition state, induced by the changes in the structure. Moreover, this difference further highlights the tune-ability of the transamination reaction by looking at the steric nature of the utilised amines. Following these model studies, the use of AE monomers to obtain VU vitrimers was investigated on material level.

\section{Material properties}

In a following stage, the $\mathrm{AE}$ chemistry was investigated at $\mathrm{VU}$ vitrimers level. Vitrimers based on either $\mathrm{AE}$ and $\mathrm{AA}$ should in principle be chemically identical and lead to similar material 
properties. However, due to the aforementioned side reaction observed for $\mathrm{AE}$, it should be checked how this would impact the properties. Thus, a comparative study was made between materials prepared from a 1,6-hexanediol functionalised with either $\mathrm{AE}$ (Hex-AE) or AA moieties (Hex-AA). Moreover, in order to assess the possible formation of alkyne amide side product during the material preparation, Hex-AE was reacted with 2.5 eq. of butylamine (leading to the model compounds Hex-AE-VU and Hex-AA-VU). NMR and LCMS analyses were used to follow the model reaction (Figure S.9 and S.10) and indicated the presence of $4.4 \%$ alkyne amide product.

Hex-AE and Hex-AA were both combined with isophorone diamine (IPDA) and tris(2aminoethyl)amine (TREN) in a ratio of 1:0.735:0.21 respectively as shown in Scheme 3 to obtain VU vitrimers with $5 \%$ excess amine.

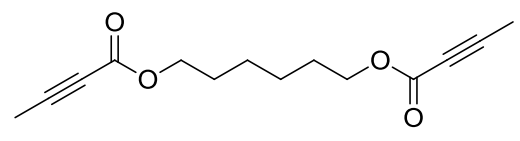

Hex-AE

or

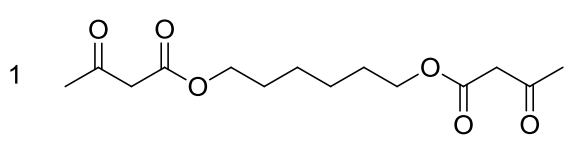

$+\quad 0.735$

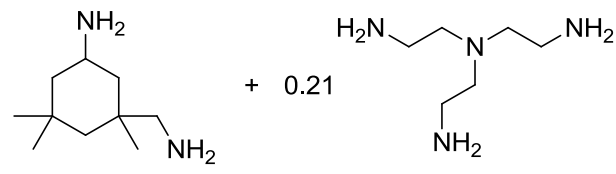

Hex-AA

Scheme 3: The used composition for both VU-AE and VU-AA. 
a)

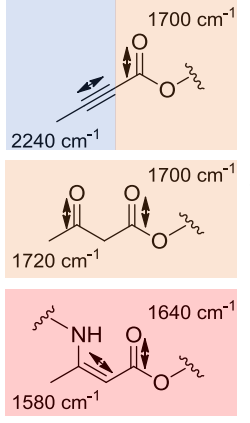

c)
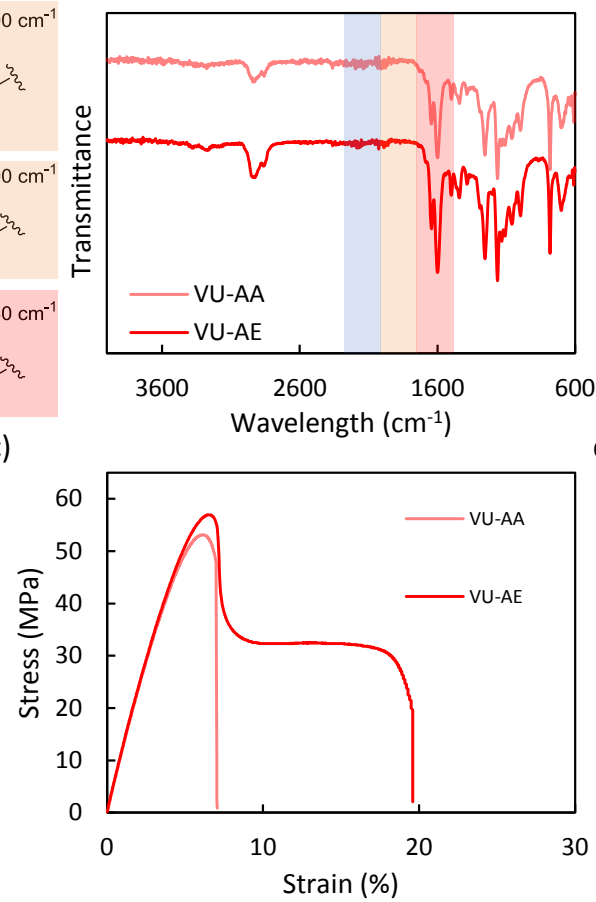

b)

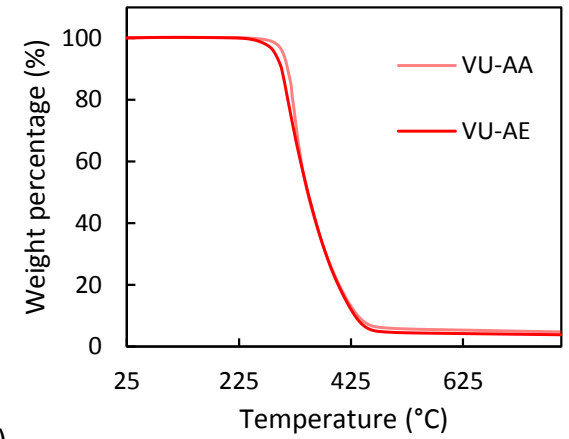

d)

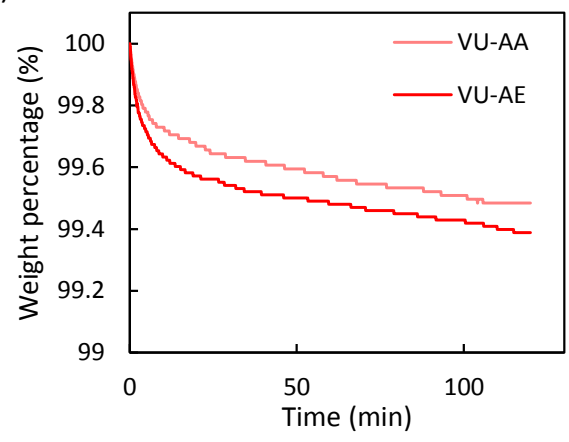

Figure 5: a) FT-IR spectrum of VU-AA and VU-AE. b) TGA of VU-AA and VU-AE with a temperature ramp from 25 to $800{ }^{\circ} \mathrm{C}$ at $10{ }^{\circ} \mathrm{C}$.min-1. c) Stress-strain curves of VU-AA and VUAE. d) Isothermal TGA of VU-AA and VU-AE at $160{ }^{\circ} \mathrm{C}$ for 120 minutes.

Full conversion of Hex-AE and Hex-AA into their respective networks (VU-AE and VU-AA) was confirmed via FT-IR measurements (Figure 5a). Indeed, the characteristic VU stretch $\left(1640 \mathrm{~cm}^{-1}\right.$ and $\left.1580 \mathrm{~cm}^{-1}\right)$ could be observed while the $\mathrm{AE}\left(2240 \mathrm{~cm}^{-1}\right.$ and $\left.1700 \mathrm{~cm}^{-1}\right)$ or the AA $\left(1720 \mathrm{~cm}^{-1}\right.$ and $\left.1700 \mathrm{~cm}^{-1}\right)$ stretches were no longer visible. Following this, their thermal properties were investigated via DSC and TGA analysis and the results are shown in Table 2. Both networks were found to possess very similar $\mathrm{T}_{\mathrm{g}}$ values $\left(67^{\circ} \mathrm{C}\right.$ and $69^{\circ} \mathrm{C}$ for VU-AE and VU-AA respectively). Moreover, they displayed good thermal stability with $\mathrm{T}_{\mathrm{d} 5 \%}$ values above $280{ }^{\circ} \mathrm{C}$ (Figure 5b) and less than $1 \%$ weight loss after 120 minutes at $160{ }^{\circ} \mathrm{C}$ (Figure $5 \mathrm{~d}$ ). These thermal stability values for VU-AE are promising, as it shows that the side-products formed during network formation do not greatly influence the service temperature. 
Then, the network integrity was investigated via swelling and solubility experiments in THF. The swelling ratio of VU-AE was nearly 4 times larger with a value of $1010 \%$ compared to $285 \%$ for VU-AA (Table 2). This large difference could be related to several factors. It could be that a small percentage of side-product can have a drastic influence on the network connectivity or that the side-product is more prevalent on material level than the model studies suggest. Another explanation could be that the VU formation reaction has a lower reaction efficiency when starting from AE monomers compared to starting from AA monomers. Moreover, the difference in network connectivity was also observed in the soluble fractions, as VU-AE lost over a quarter of its weight in THF, while VU-AA only lost $7 \%$.

Table 2: Number of recycling steps, thermal properties, swelling ratio and soluble fractions, tensile properties, activation energy and characteristic relaxation times of the investigated vitrimers.

\begin{tabular}{|c|c|c|c|c|c|c|c|c|c|c|}
\hline Networks & $\begin{array}{l}\text { Recycling } \\
\text { steps }\end{array}$ & $\begin{array}{c}\mathbf{T}_{\mathbf{g}}{ }^{\mathbf{a}} \\
\left({ }^{\circ} \mathbf{C}\right)\end{array}$ & $\begin{array}{l}\mathbf{T}_{\mathbf{d 5} \%}{ }^{b} \\
\left({ }^{\circ} \mathrm{C}\right)\end{array}$ & $\begin{array}{c}\text { Iso TGA } \\
(w t \%)\end{array}$ & $\begin{array}{c}\text { Swelling } \\
\text { Ratio }^{\mathrm{d}} \\
(\%)\end{array}$ & $\begin{array}{c}\text { Soluble } \\
\text { Fraction }^{\mathrm{e}} \\
(\%)\end{array}$ & $\begin{array}{c}\varepsilon^{\mathrm{f}} \\
(\%)\end{array}$ & $\begin{array}{c}\mathbf{E}^{, \mathbf{f}} \\
(\mathbf{M P a})\end{array}$ & $\begin{array}{c}E_{a} \\
\left(\mathrm{~kJ} . \mathrm{mol}^{-1}\right)\end{array}$ & $\begin{array}{l}\tau_{150^{\circ} \mathrm{C}}^{*} \\
\text { (s) } \\
\end{array}$ \\
\hline \multirow{5}{*}{ VU-AE } & $\mathrm{Rx} 0$ & 67 & 289 & 0.61 & 1010 & 26 & $28.8 \pm 20.5$ & $1300 \pm 49$ & $177 \pm 6$ & 27 \\
\hline & $\mathrm{Rx} 1$ & 65 & 287 & 0.76 & $*$ & $*$ & $15.2 \pm 13.5$ & $1280 \pm 75$ & $*$ & $*$ \\
\hline & $\mathrm{Rx} 2$ & 65 & 288 & 0.65 & $*$ & $*$ & $5.2 \pm 0.9$ & $1230 \pm 40$ & $*$ & $*$ \\
\hline & $\mathrm{Rx} 3$ & 66 & 288 & 0.58 & $*$ & $*$ & $2.7 \pm 1.2$ & $1140 \pm 62$ & * & * \\
\hline & $\mathrm{Rx} 4$ & 67 & 288 & 0.68 & 510 & 17 & $3.7 \pm 2.0$ & $1250 \pm 37$ & $218 \pm 11$ & 78 \\
\hline VU-AA & $\mathrm{Rx} 0$ & 69 & 304 & 0.52 & 285 & 7 & $6.7 \pm 2.0$ & $1190 \pm 87$ & $140 \pm 7$ & 120 \\
\hline
\end{tabular}

${ }^{a}$ Glass transition temperature (Tg) determined during second heating by differential scanning calorimetry (DSC) with a heating and cooling rate of $10{ }^{\circ} \mathrm{C} \cdot \mathrm{min}-1 .{ }^{\mathrm{b}}$ Temperature at which a mass loss of $5 \%$ is observed by thermogravimetric analysis (TGA). ${ }^{c}$ Mass loss after an isothermal TGA measurement of 120 minutes at $160{ }^{\circ} \mathrm{C}$. ${ }^{\mathrm{d}}$ Determined after $24 \mathrm{~h}$ in $\mathrm{THF}$ via Equation S.2; ${ }^{\text {e }}$ Determined via Equation S.1 after $24 \mathrm{~h}$ in THF and dried for $24 \mathrm{~h}$ in a vacuum oven at $40{ }^{\circ} \mathrm{C}$. ${ }^{\mathrm{f}}$ Elongation at break $(\varepsilon)$ and apparent Young's modulus (E') determined from tensile testing $(0.05 \mathrm{~N}$ preload and $10 \mathrm{~mm} . \mathrm{min}-1)$ with strain being measured as [actuator displacement]/[gauge length]. These values are relative and used for comparison purposes only. * Not performed. 
In a next step, the tensile properties of both vitrimers were investigated. Unsurprisingly, VUAE, with an elongation of $28.8 \pm 20.5 \%$, turned out to be more flexible than VU-AA, which only displayed an elongation of $6.7 \pm 2.0 \%$ (Figure $5 \mathrm{c}$ and Table 2 ). This large difference comes from the fact that VU-AE exhibited a high amount of necking and drawing, most likely due to the plasticising effect of the side-product and the lower cross-link density. Furthermore, despite this lower cross-link density and longer elongation, the E' values for VU-AE and VU-AA were approximately the same $(1.3 \mathrm{GPa})$.

Lastly, the viscoelastic properties of the materials were analysed via stress-relaxation. The stress-relaxation of VU-AE, as seen in Figure S.24a, occurred at a remarkably faster rate than the one of VU-AA (Figure S.24b). Indeed, relaxation times of $26.5 \mathrm{~s}$ and $120 \mathrm{~s}$ at $150{ }^{\circ} \mathrm{C}$ were obtained for VU-AE and VU-AA respectively. This faster relaxation rate is ascribed to a reduced cross-link density and the presence of low molecular weight compounds and thus a higher internal mobility of the chains for VU-AE. Additionally, hydroxyl groups have an accelerating effect on the stress-relaxation rate $\mathrm{e}^{33}$ and, due to the transamidation side reaction, a small amount of these groups should be present in VU-AE. Furthermore, the Arrhenius plots (Figure 6a and b) display a highly linear behaviour and high activation energies were obtained $(177 \pm 6$ and $140 \pm$ $7 \mathrm{~kJ} \cdot \mathrm{mol}^{-1}$ for VU-AE and VU-AA respectively). These high activation energies could be the result of the used diamine. IPDA (Scheme 3) has two primary amines located on differently substituted carbons (primary vs secondary carbon), which were already found to behave differently in the VU synthesis and to have an influence on the transamination reaction. Therefore, the higher $\mathrm{E}_{\mathrm{a}}$ could be the result of the difference in steric hindrance of the primary amines. 

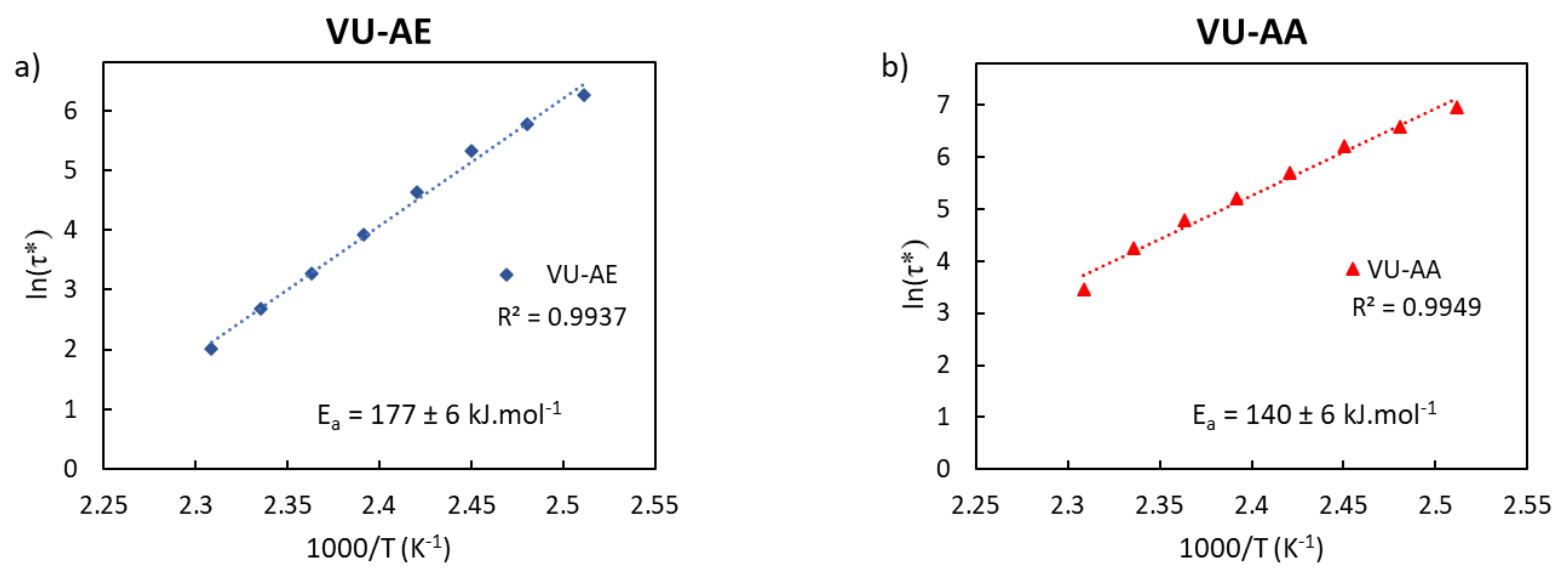

Figure 6: a) and b) Arrhenius plot of the obtained relaxation times of VU-AE and VU-AA, respectively.

Furthermore, VU-AE could also be recycled up to four times via compression moulding (150 ${ }^{\circ} \mathrm{C}$ for 35 minutes) after the material was broken into smaller pieces (Figure S.32). Tensile and thermal properties, as well as FT-IR were measured after each recycling step (Table 2 and Figure S.13, S.18 and S.29). The thermal properties and the chemical nature of the material remained practically unchanged. Furthermore, the apparent Young's modulus of VU-AE also stayed virtually the same with only a $50 \mathrm{MPa}$ difference between the pristine and the four times recycled sample. However, the elongation was drastically reduced after the second recycling step, as the material seemed to have lost its ability for necking. Additionally, after four recycling steps, the swelling and soluble fraction were measured again, and lower swelling ratio (510\%) and soluble fraction $(17 \%)$ were observed. These latter changes indicate either the presence of some undesired side-reactions, changes in the matrix or the oxidation of pendent amines and seem to also result in further discolouration of the material (Figure S.32). Furthermore, the stress-relaxation rate also slowed down as a relaxation time of $78 \mathrm{~s}$ was obtained at $150{ }^{\circ} \mathrm{C}$ compared to $27 \mathrm{~s}$ for the unrecycled sample. Moreover, the calculated activation energy also increased to $218 \pm 11 \mathrm{~kJ} \mathrm{~mol}^{-1}$ and the linearity in the Arrhenius plot decreased (Figure S.25). 
These results could be related to the oxidation of pendent amines and the potential presence of additional cross-linking reactions as this could affect the viscous flow behaviour of the material and the resulting viscous flow activation energy. Nevertheless, the VU-AE material is proven to be recyclable up to four times with only minor loss of material properties.

All these observations indicate that, despite the theoretical possibility of obtaining two chemically identical materials from AE and AA monomers, significant experimental differences are observed. However, this amide formation does not seem prohibitive for network synthesis, and may even be exploited to the benefit of the material design.

\section{One-pot water-free VU epoxy vitrimers}

Lastly, to showcase the possibilities of AE monomers to be used as additive in epoxy resins, some vinylogous urethane containing epoxy vitrimers were prepared. As previously mentioned, the advantage of AE type monomers is that they can be used as an additive in epoxy resins as a real drop-in technology to produce water-free VU containing epoxy vitrimers. Moreover, the material composition can be easily tuned with $\mathrm{AE}$ monomers regarding cross-link density and VU content, as it only needs to be mixed with the epoxy resin. First, an epoxy vitrimer (referred as $\mathrm{OPN}_{42 / 5} \mathrm{AE}$ ) was obtained by mixing $\mathrm{AE}$ functionalised ethylene glycol (EG-AE) together with EPIKOTETM Resin MGS LR 135, TREN and 1,3-bis(aminomethyl)cyclohexane (BAC). This composition allowed the use of an epoxy vitrimer network $\left(\mathrm{OPN}_{42 / 5}\right)$ based on acetoacetylated ethylene glycol, previously reported by our group, as a reference material. The same synthetic procedure and ratios as the ones utilised for $\mathrm{OPN}_{42 / 5}$ were also used for the synthesis of $\mathrm{OPN}_{42 / 5}-\mathrm{AE}$. The latter was then fully characterised and compared to the reported $\mathrm{OPN}_{42 / 5}$ (see Table 3). FT-IR spectra were also obtained and can be found in the SI (Figure S.1417). 
Table 3: Ratio of bisamine:trisamine, number of recycling steps, thermal properties, swelling ratio and soluble fractions, tensile properties, activation energy and characteristic relaxation time of the investigated vitrimers.

\begin{tabular}{|c|c|c|c|c|c|c|c|c|c|c|}
\hline Networks & $\begin{array}{c}\text { Ratio } \\
\text { amines }^{\text {a }}\end{array}$ & $\begin{array}{l}\text { Recycling } \\
\text { steps }\end{array}$ & $\begin{array}{c}\mathbf{T}_{\mathbf{g}}^{\mathbf{b}} \\
\left({ }^{\circ} \mathbf{C}\right)\end{array}$ & $\begin{array}{l}\mathbf{T}_{\mathbf{d 5 \%}}{ }^{\mathrm{c}} \\
\left({ }^{\circ} \mathrm{C}\right)\end{array}$ & 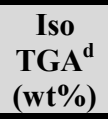 & $\begin{array}{c}\text { Soluble } \\
\text { Fraction }^{\text {e }} \\
(\%)\end{array}$ & $\begin{array}{c}\varepsilon^{\mathrm{f}} \\
(\%)\end{array}$ & $\begin{array}{c}\mathbf{E}^{, \mathbf{f}} \\
(\mathrm{MPa})\end{array}$ & $\underset{\left(k J . m_{a l}^{-1}\right)}{E_{a}}$ & $\begin{array}{l}\tau_{150^{\circ} \mathrm{C}}^{*} \\
\text { (s) }\end{array}$ \\
\hline \multirow{3}{*}{$\mathrm{OPN}_{42 / 5}-\mathrm{AE}$} & \multirow{3}{*}{$3.5: 1$} & $\mathrm{Rx} 0$ & 69 & 249 & 0.70 & 2.4 & $10.7 \pm 5.0$ & $1520 \pm 79$ & $92 \pm 1$ & 4 \\
\hline & & $\mathrm{Rx} 1$ & 72 & 242 & 0.89 & $*$ & $5.3 \pm 1.5$ & $1710 \pm 79$ & $*$ & $*$ \\
\hline & & $\mathrm{Rx} 2$ & 70 & 252 & 1.49 & $*$ & $3.2 \pm 0.3$ & $1760 \pm 43$ & $*$ & $*$ \\
\hline \multirow{3}{*}{$\mathrm{OPN}_{42 / 5}{ }^{33}$} & \multirow{3}{*}{$3.5: 1$} & $\mathrm{Rx} 0$ & 74 & 250 & 0.9 & 5.0 & $10.6 \pm 2.0$ & $1680 \pm 25$ & $100 \pm 1$ & 7 \\
\hline & & $\mathrm{Rx} 1$ & 74 & * & $*$ & $*$ & $3.9 \pm 1.7$ & $1710 \pm 101$ & $*$ & $*$ \\
\hline & & $\mathrm{Rx} 2$ & 73 & * & $*$ & $*$ & $3.7 \pm 0.8$ & $1620 \pm 36$ & $*$ & $*$ \\
\hline
\end{tabular}

${ }^{a}$ The ratio of the used bisamine:trisamine. ${ }^{b}$ Glass transition temperature $\left(\mathrm{T}_{\mathrm{g}}\right)$ determined during second heating by differential scanning calorimetry (DSC) with a heating and cooling rate of $10{ }^{\circ} \mathrm{C} \cdot \mathrm{min}-1{ }^{\mathrm{c}}$ Temperature at which a mass loss of $5 \%$ is observed by thermogravimetric analysis (TGA). ${ }^{\mathrm{d}}$ Mass loss after an isothermal TGA measurement of 120 minutes at $160{ }^{\circ} \mathrm{C}$. ${ }^{\mathrm{e}}$ Determined by Soxhlet extraction in toluene at reflux temperature for $24 \mathrm{~h}$ via Equation V.3. ${ }^{\mathrm{f}}$ Elongation at break $(\varepsilon)$ and apparent Young's modulus (E') determined from tensile testing $(0.05 \mathrm{~N}$ preload and $10 \mathrm{~mm} . \mathrm{min}-1)$ with strain being measured as [actuator displacement]/[gauge length]. These values are relative and used for comparison purposes only. ${ }^{*}$ Not performed.

In line with the comparison between VU-AE and VU-AA, similar thermal properties $\left(\mathrm{T}_{\mathrm{g}}, \mathrm{T}_{\mathrm{d} 5 \%}\right.$ and weight loss in isothermal TGA) were obtained for $\mathrm{OPN}_{42 / 5}-\mathrm{AE}$ and $\mathrm{OPN}_{42 / 5}$ (Table 3, Figure S.19 and S.23). However, in contrast to the previous comparison, a lower soluble fraction for the AE network was obtained. This could be ascribed to multiple factors, such as a lower swelling due to slightly changed matrix or the occurrence of unexpected cross-linking reactions in combination with the epoxy matrix. Nevertheless, the lower soluble fraction is definitely a good sign for the potential of utilising AE monomers in combination with epoxy resins. Following this, similar trends in tensile properties are observed, in which the elongation decreases with recycling steps and the Young's modulus remained the same or increased slightly (Table 3 and Figure S.30). Lastly, the viscoelastic properties were compared (Figure S.26). As expected, the stress-relaxation rate of $\mathrm{OPN}_{42 / 5}-\mathrm{AE}$ was found to be faster than the one of $\mathrm{OPN}_{42 / 5}$ with a 
relaxation time of $4 \mathrm{~s}$ compared to $7 \mathrm{~s}$ at $150{ }^{\circ} \mathrm{C}$. Again, this could be due to the larger presence of hydroxyl moieties in the AE network or because of the presence of low molecular weight compounds acting as a plasticiser. Furthermore, a near perfect linear behaviour could be observed in the Arrhenius plot of Figure S.26. The resulting viscous flow $E_{a}$ of $\mathrm{OPN}_{42 / 5}-\mathrm{AE}$ $\left(92 \pm 1 \mathrm{~kJ} \cdot \mathrm{mol}^{-1}\right)$ was similar to the one of $\mathrm{OPN}_{42 / 5}\left(100 \pm 1 \mathrm{~kJ} \cdot \mathrm{mol}^{-1}\right)$.

These results clearly validate the use of $\mathrm{AE}$ monomers in order to obtain vinylogous urethane containing epoxy vitrimers in a water-free manner and further highlight the versatility of this novel functional handle for the formation of VU vitrimers. Additional materials were also synthesised to highlight the versatility of the AE approach and can be found in the supporting info (section IV).

\section{Conclusion}

This study demonstrated that alkyne esters can replace acetoacetate monomers for the preparation of vinylogous urethane vitrimers, leading to a more attractive polyaddition process of the dynamic networks, avoiding the release of water. Therefore, AE offers a solution for one of the main technical issues regarding the direct synthesis of VU vitrimer materials without waterinduced defects. Small molecule model studies, supported by DFT calculations, indicate that AE can indeed be used to synthesise VU, however, these also showed that an alkyne amide sideproduct is obtained next to the desired VU. Its formation can be reduced to below $5 \%$ in these model studies. Here, it was also noticed that $\mathrm{AE}$ have a much higher reactivity towards amines than acetoacetates as binding partners, and that VU bonds can also be obtained from less reactive amine monomers, not usable in classical VU polymerization, thus also increasing the scope of viable VU amine monomers. VU network synthesis also showed this side reaction, but nevertheless, besides a higher soluble fraction, the network obtained from an AE monomer 
displayed similar or better properties compared to a network obtained from an identical AA monomer. Moreover, VU-AE network displayed significantly faster stress-relaxation compared to VU-AA, possibly related to the hydrogen bond donating character of the amide side product as an embedded or internal catalyst. Additionally, polyaddition curing of epoxy vitrimers could be easily achieved with this novel approach, in a one-pot method, contacting amine, epoxy and AE monomers, giving defect-free epoxy networks. This also means that AE monomers can be seen as an easy drop-in method to obtain processable epoxy materials, as they can be easily added into epoxy resins as additives, with easy tuneability of the final VU content and cross-link density as a result.

\section{Associated content}

Supporting Information. Supplemental figures, tables, schemes and pictures, additional material characterization and coordinates for the computational calculations.

\section{Author information}

\section{Corresponding authors}

*E-mail: Filip.DuPrez@UGent.be and Johan.Winne@UGent.be

\section{Author Contributions}

The manuscript was written through contributions of all authors. All authors have given approval to the final version of the manuscript.

\section{Notes}

The authors declare no competing financial interest.

\section{Acknowledgements}


Y.S (FWO.3F0.2016.0039.01) and N.V.H. (FWO.SPB.2016.0049.01) acknowledge the Research Foundation-Flanders (Fonds Wetenschappelijk Onderzoek-Vlaanderen) for Ph.D. and Postdoctoral fellowships. F.E.D.P and J.W. acknowledges UGent funding (BOF-GOA). B. De Meyer, J. Goeman, and T. Courtin are thanked for technical support. The computational resources (Stevin Supercomputer Infrastructure) and services used in this work were provided by the VSC (Flemish Supercomputer Center), funded by Ghent University, FWO and the Flemish Government—department EWI.

References

(1) Kloxin, C. J.; Bowman, C. N. Covalent adaptable networks: smart, reconfigurable and responsive network systems. Chemical Society Reviews 2013, 42 (17), 7161.

(2) Bowman, C. N.; Kloxin, C. J. Covalent Adaptable Networks: Reversible Bond Structures Incorporated in Polymer Networks. Angewandte Chemie International Edition 2012, 51 (18), 4272.

(3) Kloxin, C. J.; Scott, T. F.; Adzima, B. J.; Bowman, C. N. Covalent Adaptable Networks (CANs): A Unique Paradigm in Cross-Linked Polymers. Macromolecules 2010, 43 (6), 2643.

(4) Winne, J. M.; Leibler, L.; Du Prez, F. E. Dynamic covalent chemistry in polymer networks: a mechanistic perspective. Polymer Chemistry 2019, 10 (45), 6091.

(5) Denissen, W.; Winne, J. M.; Du Prez, F. E. Vitrimers: permanent organic networks with glass-like fluidity. Chemical science 2016, 7 (1), 30. 
(6) Scheutz, G. M.; Lessard, J. J.; Sims, M. B.; Sumerlin, B. S. Adaptable Crosslinks in Polymeric Materials: Resolving the Intersection of Thermoplastics and Thermosets. Journal of the American Chemical Society 2019, 141 (41), 16181.

(7) Van Zee, N. J.; Nicolaÿ, R. Vitrimers: Permanently crosslinked polymers with dynamic network topology. Progress in Polymer Science 2020, 104, 101233.

(8) Krishnakumar, B.; Sanka, R.; Binder, W. H.; Parthasarthy, V.; Rana, S.; Karak, N. Vitrimers: Associative dynamic covalent adaptive networks in thermoset polymers. Chem. Eng. J. 2020, 385, 13.

(9) Guerre, M.; Taplan, C.; Winne, J. M.; Du Prez, F. E. Vitrimers: directing chemical reactivity to control material properties. Chemical science 2020, 11 (19), 4855.

(10) Montarnal, D.; Capelot, M.; Tournilhac, F.; Leibler, L. Silica-Like Malleable Materials from Permanent Organic Networks. Science 2011, 334 (6058), 965.

(11) Hayashi, M.; Yano, R. Fair Investigation of Cross-Link Density Effects on the BondExchange Properties for Trans-Esterification-Based Vitrimers with Identical Concentrations of Reactive Groups. Macromolecules 2020, 53 (1), 182.

(12) Altuna, F. I.; Hoppe, C. E.; Williams, R. J. J. Epoxy vitrimers with a covalently bonded tertiary amine as catalyst of the transesterification reaction. Eur. Polym. J. 2019, 113, 297.

(13) Niu, X.; Wang, F.; Li, X.; Zhang, R.; Wu, Q.; Sun, P. Using Zn2+ Ionomer To Catalyze Transesterification Reaction in Epoxy Vitrimer. Industrial \& Engineering Chemistry Research 2019, 58 (14), 5698. 
(14) Liu, T.; Zhang, S.; Hao, C.; Verdi, C.; Liu, W.; Liu, H.; Zhang, J. Glycerol Induced

Catalyst-Free Curing of Epoxy and Vitrimer Preparation. Macromolecular Rapid Communications 2019, 40 (7), 1800889.

(15) Xu, C.; Zheng, Z.; Wu, W.; Fu, L.; Lin, B. Design of healable epoxy composite based on $\beta$-hydroxyl esters crosslinked networks by using carboxylated cellulose nanocrystals as crosslinker. Composites Science and Technology 2019, 181, 107677.

(16) Zhou, Y.; Goossens, J. G. P.; van den Bergen, S.; Sijbesma, R. P.; Heuts, J. P. A. In Situ Network Formation in PBT Vitrimers via Processing-Induced Deprotection Chemistry. Macromolecular Rapid Communications 2018, 39 (19), 1800356.

(17) Zhang, H.; Cai, C.; Liu, W.; Li, D.; Zhang, J.; Zhao, N.; Xu, J. Recyclable Polydimethylsiloxane Network Crosslinked by Dynamic Transesterification Reaction. Scientific Reports 2017, 7, 11833.

(18) Capelot, M.; Unterlass, M. M.; Tournilhac, F.; Leibler, L. Catalytic Control of the Vitrimer Glass Transition. ACS Macro Lett. 2012, 1 (7), 789.

(19) Capelot, M.; Montarnal, D.; Tournilhac, F.; Leibler, L. Metal-Catalyzed Transesterification for Healing and Assembling of Thermosets. Journal of the American Chemical Society 2012, 134 (18), 7664.

(20) Hendriks, B.; Waelkens, J.; Winne, J. M.; Du Prez, F. E. Poly(thioether) Vitrimers via Transalkylation of Trialkylsulfonium Salts. ACS Macro Lett. 2017, 6 (9), 930.

(21) Caffy, F.; Nicolaÿ, R. Transformation of polyethylene into a vitrimer by nitroxide radical coupling of a bis-dioxaborolane. Polymer Chemistry 2019, 10 (23), 3107. 
(22) Röttger, M.; Domenech, T.; van der Weegen, R.; Breuillac, A.; Nicolaÿ, R.; Leibler, L. High-performance vitrimers from commodity thermoplastics through dioxaborolane metathesis. Science 2017, 356 (6333), 62.

(23) Cash, J. J.; Kubo, T.; Bapat, A. P.; Sumerlin, B. S. Room-Temperature Self-Healing Polymers Based on Dynamic-Covalent Boronic Esters. Macromolecules 2015, 48 (7), 2098.

(24) Cromwell, O. R.; Chung, J.; Guan, Z. Malleable and Self-Healing Covalent Polymer Networks through Tunable Dynamic Boronic Ester Bonds. Journal of the American Chemical Society 2015, 137 (20), 6492.

(25) Ricarte, R. G.; Tournilhac, F.; Cloitre, M.; Leibler, L. Linear Viscoelasticity and Flow of Self-Assembled Vitrimers: The Case of a Polyethylene/Dioxaborolane System. Macromolecules 2020, $53(5), 1852$.

(26) Bai, L.; Zheng, J. P. Robust, reprocessable and shape-memory vinylogous urethane vitrimer composites enhanced by sacrificial and self-catalysis $\mathrm{Zn}$ (II) ligand bonds. Composites Science and Technology 2020, 190, 8.

(27) Spiesschaert, Y.; Taplan, C.; Stricker, L.; Guerre, M.; Winne, J. M.; Du Prez, F. E. Influence of the polymer matrix on the viscoelastic behaviour of vitrimers. Polymer Chemistry 2020, 11 (33), 5377.

(28) Spiesschaert, Y.; Guerre, M.; Imbernon, L.; Winne, J. M.; Du Prez, F. Filler reinforced polydimethylsiloxane-based vitrimers. Polymer 2019, 172, 239. 
(29) Liu, Z.; Zhang, C.; Shi, Z.; Yin, J.; Tian, M. Tailoring vinylogous urethane chemistry for the cross-linked polybutadiene: Wide freedom design, multiple recycling methods, good shape memory behavior. Polymer 2018, 148, 202.

(30) Denissen, W.; Droesbeke, M.; Nicolaÿ, R.; Leibler, L.; Winne, J. M.; Du Prez, F. E. Chemical control of the viscoelastic properties of vinylogous urethane vitrimers. Nature Communications 2017, 8, 14857.

(31) Stukenbroeker, T.; Wang, W. D.; Winne, J. M.; Du Prez, F. E.; Nicolay, R.; Leibler, L. Polydimethylsiloxane quenchable vitrimers. Polymer Chemistry 2017, 8 (43), 6590.

(32) Denissen, W.; Rivero, G.; Nicolay, R.; Leibler, L.; Winne, J. M.; Du Prez, F. E. Vinylogous Urethane Vitrimers. Adv. Funct. Mater. 2015, 25 (16), 2451.

(33) Spiesschaert, Y.; Guerre, M.; De Baere, I.; Van Paepegem, W.; Winne, J. M.; Du Prez, F. E. Dynamic Curing Agents for Amine-Hardened Epoxy Vitrimers with Short (Re)processing Times. Macromolecules 2020, 53 (7), 2485.

(34) Taplan, C.; Guerre, M.; Winne, J. M.; Du Prez, F. E. Fast processing of highly crosslinked, low-viscosity vitrimers. Materials Horizons 2020, 7 (1), 104.

(35) Guerre, M.; Taplan, C.; Nicolay, R.; Winne, J. M.; Du Prez, F. E. Fluorinated vitrimer elastomers with a dual temperature response. J. Am. Chem. Soc. 2018, 140 (41), 13272.

(36) Taplan, C.; Guerre, M.; Bowman, C. N.; Du Prez, F. E. Surface Modification of (Non)Fluorinated Vitrimers through Dynamic Transamination. Macromolecular Rapid Communications 2021, 42, 2000644. 
(37) He, C.; Christensen, P. R.; Seguin, T. J.; Dailing, E. A.; Wood, B. M.; Walde, R. K.;

Persson, K. A.; Russell, T. P.; Helms, B. A. Conformational Entropy as a Means to Control the Behavior of Poly(diketoenamine) Vitrimers In and Out of Equilibrium. Angewandte Chemie International Edition 2020, 59 (2), 735.

(38) Hajj, R.; Duval, A.; Dhers, S.; Avérous, L. Network Design to Control Polyimine Vitrimer Properties: Physical Versus Chemical Approach. Macromolecules 2020, 53 (10), 3796.

(39) Tretbar, C. A.; Neal, J. A.; Guan, Z. B. Direct Silyl Ether Metathesis for Vitrimers with Exceptional Thermal Stability. Journal of the American Chemical Society 2019, 141 (42), 16595.

(40) Chen, M.; Zhou, L.; Wu, Y.; Zhao, X.; Zhang, Y. Rapid Stress Relaxation and Moderate Temperature of Malleability Enabled by the Synergy of Disulfide Metathesis and Carboxylate Transesterification in Epoxy Vitrimers. ACS Macro Lett. 2019, 8 (3), 255.

(41) He, C.; Shi, S.; Wang, D.; Helms, B. A.; Russell, T. P. Poly(oxime-ester) Vitrimers with Catalyst-Free Bond Exchange. Journal of the American Chemical Society 2019, 141 (35), 13753.

(42) Erice, A.; Azcune, I.; Ruiz de Luzuriaga, A.; Ruipérez, F.; Irigoyen, M.; Matxain, J. M.; Asua, J. M.; Grande, H.-J.; Rekondo, A. Effect of Regioisomerism on Processability and Mechanical Properties of Amine/Urea Exchange Based Poly(urea-urethane) Vitrimers. $A C S$ Applied Polymer Materials 2019, 1 (9), 2472.

(43) Snyder, R. L.; Fortman, D. J.; De Hoe, G. X.; Hillmyer, M. A.; Dichtel, W. R. Reprocessable Acid-Degradable Polycarbonate Vitrimers. Macromolecules 2018, 51 (2), 389.

(44) Ishibashi, J. S. A.; Kalow, J. A. Vitrimeric Silicone Elastomers Enabled by Dynamic Meldrum's Acid-Derived Cross-Links. ACS Macro Lett. 2018, 7 (4), 482. 
(45) Thomas;, B.; Tim;, D.; Kristof; H.; Jos, L.; B41C1/10 ed.; NV, A., Ed., 2017.

(46) Lessard, J. J.; Scheutz, G. M.; Sung, S. H.; Lantz, K. A.; Epps, T. H.; Sumerlin, B. S. Block Copolymer Vitrimers. Journal of the American Chemical Society 2020, 142 (1), 283.

(47) Lessard, J. J.; Garcia, L. F.; Easterling, C. P.; Sims, M. B.; Bentz, K. C.; Arencibia, S.; Savin, D. A.; Sumerlin, B. S. Catalyst-Free Vitrimers from Vinyl Polymers. Macromolecules 2019, $52(5), 2105$.

(48) Jacob, I.; Ian, P.; Alice, C.; Aristotelis, Z.; Yan, F.; Steven, W.; Frank S., B.; Julia, K. Mechanical and structural consequences of associative dynamic cross-linking in acrylic diblock copolymers, 2020.

(49) Van Herck, N.; Maes, D.; Unal, K.; Guerre, M.; Winne, J. M.; Du Prez, F. E. Covalent Adaptable Networks with Tunable Exchange Rates Based on Reversible Thiol-yne CrossLinking. Angew. Chem.-Int. Edit. 2020, 59 (9), 3609.

(50) Hartman, G. D.; Hartman, R. D.; Cochran, D. W. Nucleophilic aromatic substitution by 3-amino-2-butenoates. The Journal of Organic Chemistry 1983, 48 (22), 4119.

(51) Liu, Y.; Wu, G.; Cui, Y. Ag/CNT-catalyzed hydroamination of activated alkynes with aromatic amines. Applied Organometallic Chemistry 2013, 27 (4), 206.

(52) Parkinson, E. I.; Bair, J. S.; Cismesia, M.; Hergenrother, P. J. Efficient NQO1 Substrates are Potent and Selective Anticancer Agents. ACS Chemical Biology 2013, 8 (10), 2173.

(53) Bair, J. S.; Palchaudhuri, R.; Hergenrother, P. J. Chemistry and Biology of Deoxynyboquinone, a Potent Inducer of Cancer Cell Death. Journal of the American Chemical Society 2010, 132 (15), 5469. 
(54) Frisch, M. J.; Trucks, G. W.; Schlegel, H. B.; Scuseria, G. E.; Robb, M. A.; Cheeseman, J. R.; Scalmani, G.; Barone, V.; Petersson, G. A.; Nakatsuji, H.et al. Wallingford, CT, 2016.

(55) Krenske, E. H.; Petter, R. C.; Houk, K. N. Kinetics and Thermodynamics of Reversible Thiol Additions to Mono- and Diactivated Michael Acceptors: Implications for the Design of Drugs That Bind Covalently to Cysteines. The Journal of Organic Chemistry 2016, 81 (23), 11726.

(56) Scalmani, G.; Frisch, M. J. Continuous surface charge polarizable continuum models of solvation. I. General formalism. The Journal of Chemical Physics 2010, 132 (11), 114110.

(57) Haida, P.; Abetz, V. Acid-Mediated Autocatalysis in Vinylogous Urethane Vitrimers. Macromolecular Rapid Communications 2020, 41, 2000273.

(58) Wright, T.; Tomkovic, T.; Hatzikiriakos, S. G.; Wolf, M. O. Photoactivated Healable Vitrimeric Copolymers. Macromolecules 2019, 52 (1), 36. 


\section{For Table of Contents Only}

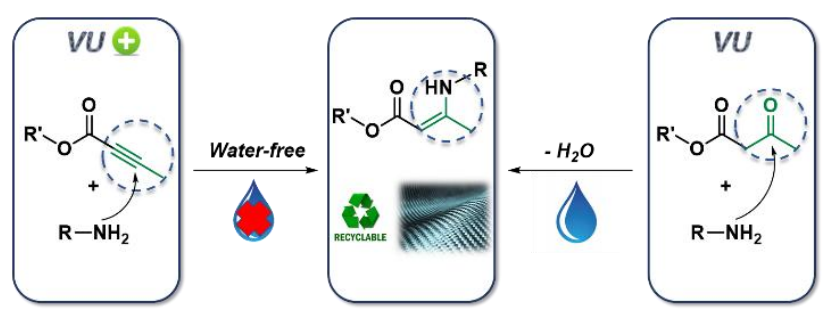

